\title{
ALTERAÇÃO DOS MINERAIS NA ZONA SUPÉRGENA DA FORMAÇÃO CUPRÍFERA DO SALOBO 3A (SERRA DOS CARAJÁS) - LOCALIZAÇÃO DO COBRE NOS PRODUTOS SECUNDÁRIOS
}

\author{
MARIA CRISTINA TOLEDO-GROKE*, DOMINIQUE PROST **, \\ PHILLIPE ILDEFONSE **;,ADOLPHO JOSE MELFI ***; \\ JEAN DELVIGNE ${ }^{* * *} \mathrm{e}$ JEAN CLAUDE PARISOT ${ }^{* * * *}$
}

\begin{abstract}
Petrographical, mineralogical, and microgeochemical studies were realized on undisturbed samples from the various weathering facies of a typical section of the Salobo $3 \mathrm{~A}$ schist sequence aiming to characterize supergenous alteration of primary minerals and locating copper. The primary paragenesis is constitued firstly of amphibole (cummingtonite-grunierite), garnet (almandine), biotite and magnetite, and secondly of chlorite, quartz, glaucophane, turmaline and there is seldom plagioclase. In weathered rocks amphiboles and garnets present pseudomorphic transformations to ferruginous products with different chemical compositions, where almost always all the iron has its origin in the mineral weathering. Biotite weathering leads to the formation of vermiculite-mixed layer which is preserved until the profile superficial horizons. Different forms of fillings (kaolinite, iron and manganese oxy-hydroxides) may be observed between the layers of these phylossilicates. In different phases of the primary minerals weathering, the copper appears associated with: a) iron oxy-hydroxides originated from the garnets and amphiboles pseudomorphose (average amount of $\mathrm{CuO}$ around 4.48 and $3.29 \%$, respectively, and $b$ ) phylossilicates originated from the biotites weathering (average amount around $7.21 \%$ ) where it is concentrated, mainly in the octaedric cavity and in interlayered position. The copper appears also associated with manganiferous products of absolute accumulation, where the average amount of $\mathrm{CuO}$ is around $20.4 \%$. These products are more recent and represent the second step of copper accumulation in the supergenous zone of Salobo 3A deposits.
\end{abstract}

INTRODUção O depósito de cobre do Salobo 3A -acha-se localizado no Distrito Mineral de Carajás, Estado do Pará, situado, aproximadamente, a $50 \mathrm{~km}$ a NW das imensas reservas de ferro da Serra dos Carajás (Fig. 1).

A região, inserida no domínio tropical úmido, encontra-se recoberta pela floresta amazônica. O clima da área é caracterizado por uma temperatura média anual de $25{ }^{\circ} \mathrm{Ce}$ pluviometria de $1.800 \mathrm{~mm} / \mathrm{ano}$, distribuída durante quase o ano todo (nove meses de estação úmida).

A mineralização primária (bornita e calcosita, com calcopirita subordinada) é, preferencialmente, encontrada em metassedimentos (xistos) ricos em ferro, que apresentam quantidades variáveis de anfíbólio, granada e magnetita. $O$ depósito cuprífero exibe uma configuração estratiforme e encontra-se intercalado entre duas formações gnáissicas. Este conjunto litológico sofreu metamorfismo de grau anfibolito-alto, seguido por retrometamorfismo de fácies xistoverde (Borges Martins et al. 1982).

Um espesso manto de alteração intempérica recobre a zona mineralizada e exibe, ele próprio, teores em cobre igualmente elevados, sem contudo apresentar sulfetos ou concentrações em minerais supérgenos de cobre que pudessem explicar os altos teores ai existentes. Desta forma, pode ser considerado um típico minério oxidado.

Neste trabalho, dedicado ao estudo do minério alterado, serão apresentados os resultados mineralógicos e geoquímicos obtidos a partir da análise de amostras dos diferentes fácies de alteração, com o objetivo de caracterizar as transformações sofridas pelos minerais silicatados, formadores da rocha mineralizada, no decorrer da alteração intempérica e, ao mesmo tempo, determinar a localização do cobre nos diferentes produtos de alteração.

Para atingir os objetivos citados, foram selecionadas amostras provenientes de furos de sonda e de galerias, utilin zadas na pesquisa mineral da área. As amostras foram estudadas através de microscopia óptica, microscopia eletrônica de varredura, difração de raio $\mathrm{X}$, análise térmica diferencial e microssonda eletrônica.

\section{EVOLUÇÃO INTEMPÉRICA DOS MINERAIS FORMA-} DORES DA ROCHA MINERALIZADA Caracterização da paragênese primária $O$ xisto mineralizado é, basicamente, constituído por anfibólio, granada, biotita e magnetita. Variações nas proporções relativas entre esses minerais explicam a grande variedade de tipos petrográficos que ocorrem na região. Vários minerais acessórios (turmalina, glaucofânio e plagioclásios) encontram-se associados aos diferentes fácies xistosos. Os sulfetos (bornita, calcopirita) estão, principalmente, associados aos fácies mais ricos em magnetita.

Anfibólio $\quad \hat{\mathrm{E}}$ o mineral mais abundante desta paragênese. Seus cristais apresentam-se freqüentemente maclados, com clivagens $(h, k, o)$ nítidas e abundantes fissuras perpendiculares. São incolores sob luz natural, mas exibem elevada birrefringência.

Eventualmente, observa-se ao redor dos cristais uma "coroa" de clorita, fruto de transformações retrometamórficas. Por outro lado, a identificação de ortopiroxênio e talco, em algumas lâminas delgadas, parece indicar que o anfibólio é, pelo menos em parte, produto de transformação do piroxênio.

\footnotetext{
* Departamento de Geologia Geral, Instituto de Geociências, USP. Cx. Postal 20899, CEP 05508, São Paulo, SP, Brasil

* Université Paris VII, 2, Place Jussieu, 75251, Paris Cedex, França

** * Departamento de Geofísica, Instituto Astronômico e Geofísico, USP. Cx. Postal 30627, CEP 01051, São Paulo, SP, Brasil

**** ORSTOM-URF5/USP. Cx. Postal 20899, CEP 05508, São Paulo, SP, Brasil
} 


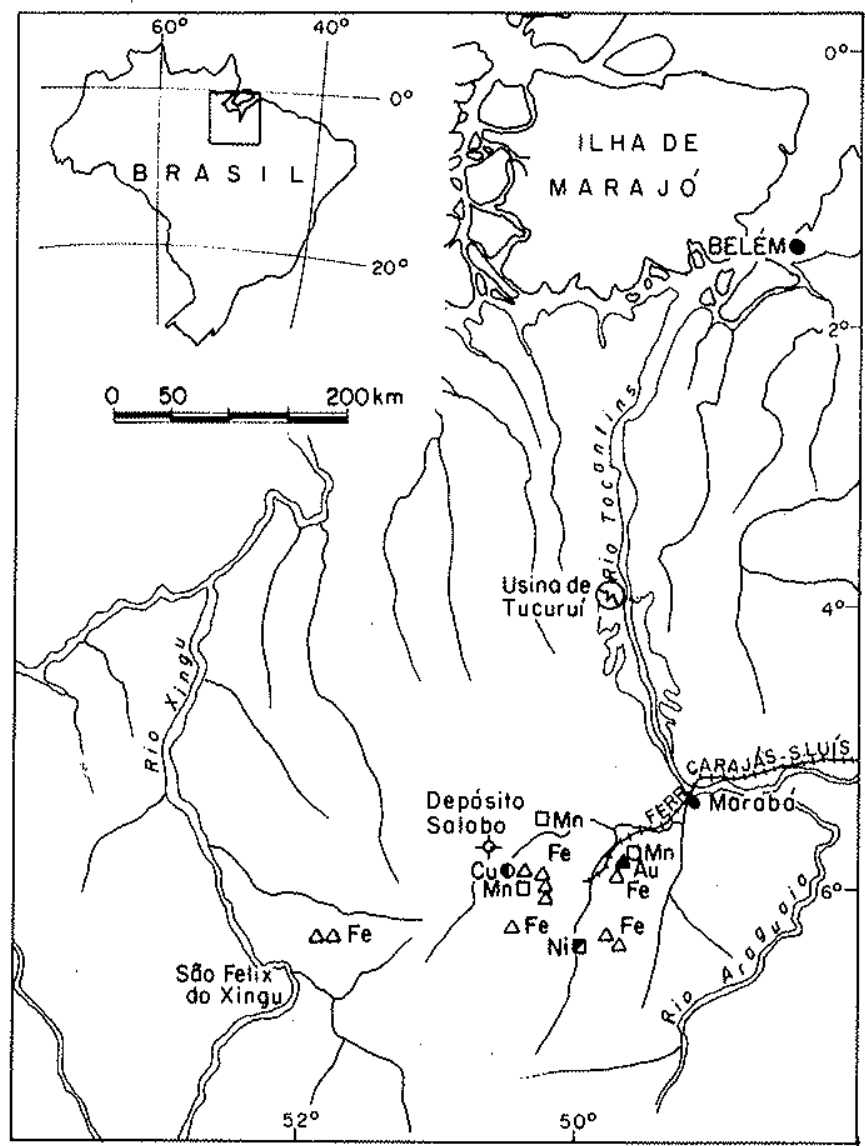

Figura 1 - Localização da área de estudo. Fonte:Docegeo/ Cvrd 1982

As análises químicas, obtidas na microssonda, permitiram calcular sua fórmula estrutural média $\left(\mathrm{Fe}_{4,87} \mathrm{Mg}_{2,06}\right.$ $\left.\mathrm{Mn}_{0,04}\right) \mathrm{Si}_{7,94} \mathrm{O}_{22}(\mathrm{OH})_{2}$, que indica tratar-se de um anfibólio cuja composição é exatamente intermediária entre a da cummingtonita e da grunerita $(71 \% \mathrm{~mol}$ grunerita e $29 \%$ mol cummingtonita).

Granada É um mineral freqüente, mas que pode estar totalmente ausente em certos fácies litológicos. Os cristais de granada apresentam-se em porfiroblastos de $1 \mathrm{~mm}$ a 2 $\mathrm{cm}$ de diâmetro, incolores, isótropos, intensamente fratura. dos e englobando outros minerais primários, como anfibólios, quartzo e opacos. Freqüentemente, as granadas são cortadas por fissuras preenchidas por cloritas e filossilicatos verdes provenientes do retrometamorfismo.

A fórmula estrutural da granada, calculada com base em análises de microssonda, é $\left(\mathrm{Fe}_{4,89} \mathrm{Mg}_{0,47} \mathrm{Mn}_{0,55} \mathrm{Cu}_{0,15}\right)$ $\left(\mathrm{Fe}_{0,12}^{3} \mathrm{Al}_{0,88}\right)\left(\mathrm{Al}_{0,17} \mathrm{Si}_{5,83}\right) \mathrm{O}_{24}$. De acordo com Deer et al (1967) tráta-se de granada do tipo almandina.

Biotita Dependendo do fácies litológico considerado, a biotita pode estar ausente ou ser o mineral dominante. Em função do pleocroísmo, as biotitas das lâminas estudadas podem ser divididas em dois tipos: biotitas com pleocroísmo castanho, mais raras; e biotitas com pleocroísmo amarelo-esverdeado, mais freqüentes. Segundo Deer et al. (op. cit.), esta diferença estaria ligada aos efeitos de uma alteração hidrotermal e/ou supérgena.

A fórmula estrutural da biotita "verde", calculada com base nas análises de microssonda, é: $\mathrm{K}_{1,88}\left(\mathrm{Mg}_{1,44} \mathrm{Ti}_{0,08}\right.$
$\left.\mathrm{Fe}_{4,4} \mathrm{Al}_{0,18}\right)\left(\mathrm{Al}_{2,56} \mathrm{Si}_{5,44}\right) \mathrm{O}_{22}(\mathrm{OH})_{2}$, tratando-se, portanto, de uma lepidomelana (Deer et al.,op. cit.)

Concluindo, percebe-se que a paragênese primária é caracterizada por minerais ricos em ferro. $O$ cobre, na forma de sulfetos, encontra-se associado aos fácies ricos em magnetita enquanto os tipos litológicos constituídos, predominantemente, por anfibólios e biotitas podem ser considerados estéreis.

Comportamento dos minerais nos niveis de alteração $O$ estudo químico e mineralógico dos diferentes horizontes do manto de alteração, que recobre a zona mineralizada, permitiu:

- verificar a persistência de certos minerais primários residuais, como, por exemplo, turmalina, que não sofre alteração e desta forma se concentra nos níveis superiores do manto intempérico;

- observar a evolução de outros minerais, como anfibólios, biotitas e granadas, fortemente alterados no curso do intemperismo (fases de alteração intramineral);

- finalmente, caracterizar fases de alteração interminerais formadas por acumulação absoluta de produtos depositados nas fissuras e nos diferentes tipos de porosidade (meio fis-. sural).

Alterações dos Minerais Anfibólio $\mathrm{O}$ estudo morfológico (Fig. 2) e geoquímico (Tab. 1) permitiu distinguir três estágios distintos na alteração dos anfibólios.

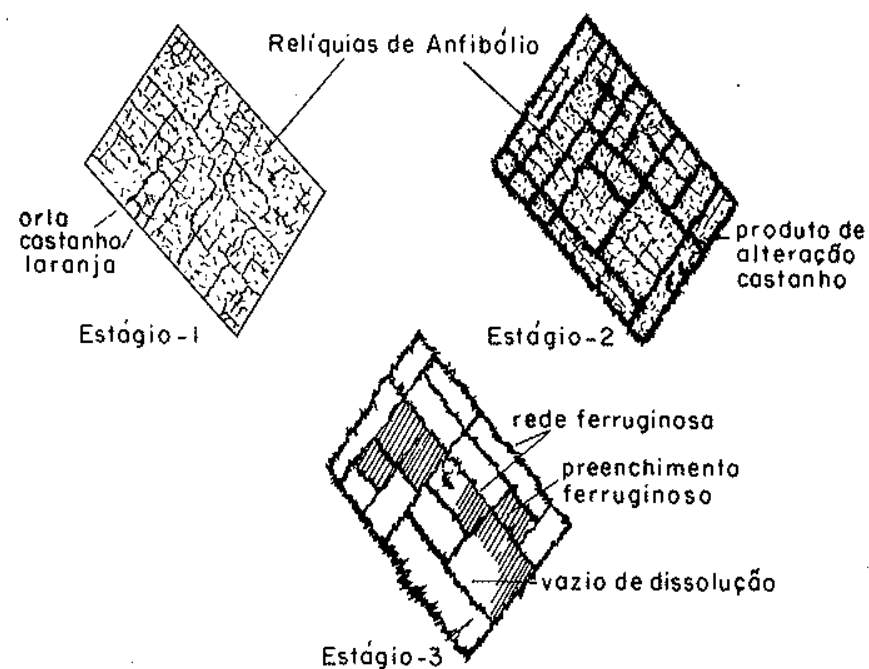

Figura 2 -Distinção morfológica dos três estágios de alterafão dos anfibólios

Tabela 1 - Análises microgeoquímicas dos produtos de alteração dos anfibólios

\begin{tabular}{l|c|c|c|c|c|c|c|c|c}
\hline & \multicolumn{2}{|c|}{ CAC 25 } & \multicolumn{3}{c|}{ CAC 17 } & \multicolumn{1}{c|}{ CAC 21 } & \multicolumn{3}{c}{ CAC 4 } \\
\cline { 2 - 10 } & 1 & 2 & 3 & 4 & 5 & 6 & 7 & $\mathbf{3}$ & 9 \\
\hline $\mathrm{SiO}_{2}$ & 50,44 & 56,38 & 45,14 & 47,95 & 46,00 & 8,88 & 9,64 & 4,72 & 8,18 \\
$\mathrm{Al}_{2} \mathrm{O}_{3}$ & 0,83 & $\ldots$ & 27,49 & 26,15 & 27,08 & 13,72 & 6,97 & 4,01 & 6,06 \\
$\mathrm{TiO}_{2}$ & $\ldots$ & $\ldots$ & $\ldots$ & $\ldots$ & $\ldots$ & 0,54 & 0,41 & $\ldots$ & 0,28 \\
$\mathrm{FeO}$ & 38,86 & 31,36 & 11,24 & 10,82 & 10,63 & 68,51 & 57,05 & 66,12 & 60,17 \\
$\mathrm{MgO}$ & 7,60 & 0,72 & 0,25 & 0,74 & $\ldots$ & $\ldots$ & 1,49 & $\ldots$ & 0,46 \\
$\mathrm{CuO}$ & $\ldots$ & 0,35 & 2,99 & 1,59 & 2,89 & 4,72 & 4,18 & 3,81 & 2,85 \\
$\mathrm{CaO}$ & 0,26 & $\ldots$ & $\ldots$ & $\ldots$ & $\ldots$ & $\ldots$ & $\ldots$ & $\ldots$ & $\ldots$ \\
$\mathrm{Na}_{2} \mathrm{O}$ & $\ldots$ & 0,61 & $\ldots$ & $\ldots$ & $\ldots$ & $\ldots$ & $\ldots$ & $\ldots$ & $\ldots$ \\
$\mathrm{K}_{2} \mathrm{O}$ & $\ldots$ & 0,73 & 0,52 & 0,22 & 0,51 & 0,29 & 0,92 & $\ldots$ & 0,19 \\
$\mathrm{Total}$ & 98,23 & 90,65 & 87,70 & 87,59 & 87,11 & 96,66 & 81,06 & 79,49 & 78,65 \\
\hline
\end{tabular}

1. Anfibólio inalterado. 2. Orla castanho-laranja; estágio 1.

3, 4 e 5. Produto de alteração castanho; estágio $2.6,7,8$ e

9. Rede ferruginosa box-work; estágio 3 
1. Aparecimento, no microssistema de contato, de uma orla ferruginosa, castanho-laranja, tanto ao redor do cristal como nas clivagens e fissuras internas. Este material é quimicamente semelhante ao anfibólio, com exceção do magnésio, que se apresenta quase totalmente lixiviado.

2. Aumento da espessura das orlas, onde persistem relíquias isoladas de anfibólio na parte central de cada célula formada pelas orlas ferruginosas, neste estágio representado por um produto de alteração castanho. Morfologicamen. te, este material é comparável ao precedente, porém difere quimicamente pela maior riqueza em $\mathrm{Al}$ e presença de $\mathrm{Cu}$.

3. Desaparecimento das relíquias 'de anfibólio. A forma do antigo cristal é preservada por uma rede ferruginosa (estrutura tipo box-work), constituída principalmente por goethita, que acompanha o padrão de descontinuidade do anfibólio original (Foto 1). As cavidades da estrutura box-work podem ou não apresentar preenchimentos de oxi-hidróxidos de ferro, de aspecto poroso, formando depósitos cutânicos.

Neste processo de alteração dos produtos ferruginosos secundários, o ferro provém da evolução do próprio anfibólio, porém o cobre e o alumínio são alóctones, o que indica a existência de transferências interminerais.

Granada A alteração das granadas inicia-se pelas descon. tinuidades criadas pelas fissuras, segundo um padrão linear irregular. Podemos também dividi-la em estágios, que se diferenciam tanto morfológica (Fig. 3) como geoquimicamente (Tab. 2).
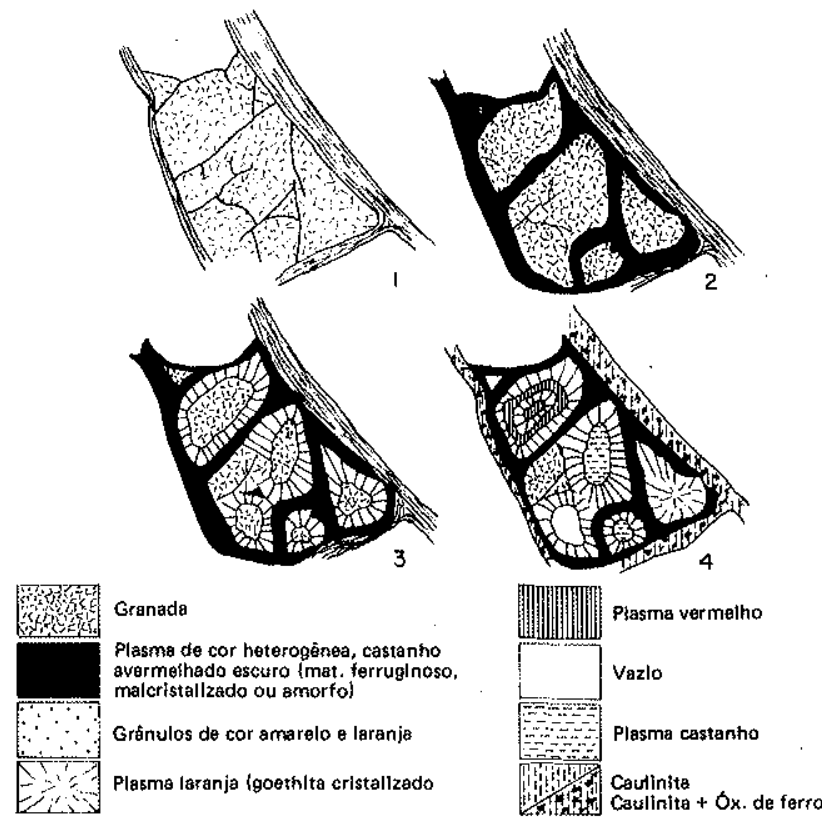

Figura 3 - Esquema de alteração das granadas

1. Formação, no microssistema de contato, constituída pelas descontinuidades de um plasma castanho a preto, de aspecto amorfo ao microscópio. Sua composição química é variável, na qual domina $\mathrm{Fe}$ e $\mathrm{Si}$, com Al subordinado; o $\mathrm{Cu}$ já se encontra presente nesta fase. Este material divide a granada em células, cada uma contendo relíquia de granada sã na parte central.

2. Alteração centrípeta da granada, quando se forma uma coroa alaranjada com aspecto de goethita bem cristaliza- da (ao microscópio óptico). Quimicamente, os teores de $\mathrm{Fe}$ e $\mathrm{Cu}$ são mais elevados que os encontrados no material formado no primeiro estágio, enquanto $\mathrm{Al}$ e Si são mais baixos. Tem-se, portanto, exportação significativa de $\mathrm{Al}$ e $\mathrm{Si}$, total do $\mathrm{Mn}$ e aporte de $\mathrm{Cu}$, que não existia na granada sã; o $\mathrm{Fe}$, concentrado residualmente na alteração da granada, poderia ser em parte, também, alóctone (Parisot et al. 1983).

Este estágio é atingido cerca de $5 \mathrm{~m}$ acima da rocha sã, quando a biotíta e o anfibólio estão ainda no início da alteração. Esta evolução difere da estudada por Embrechts \& Stoops (1982) e Sarazin et al. (1982), na qual este estágio é atingido em níveis mais superiores.

3. Neste estágio, encontram-se várias situaçōes (Fotos 2,3 e 4).

- Aparecimento de um plasma castanho, entre a coroa alaranjada e a granada ainda sã; este plasma desenvolve-se à custa da granada central até seu total desaparecimento.

- Formação de um plasma alaranjado, com parte central vazia ou preenchida por grânulos de cor amarela ou laranja. - Aparecimento de um plasma alaranjado, com plasma castanho poroso-granulado no centro.

- Alternância de plasma alaranjado e de plasma vermelho.

Todos esses materiais secundários contêm cobre na faixa de $1 \%$ a $5 \%$ em CuO.

Nas amostras mais alteradas, ocorre um material preto que ocupa os vazios intra e intercelulares, com teores da ordem de $73 \%$ em $\mathrm{MnO}$ e $8 \%$ em $\mathrm{CuO}$; corresponde a um plasma de acumulação absoluta, independente das transformações acima.

Nas fissuras, que ocorrem preenchidas por esmectitas ou caulinita, só existe cobre quando, associados, aparecem óxi"hidróxidos de ferro.

Biotita A evolução das biotitas apresenta-se conforme as descrições clássicas de alteração, como, por exemplo, a feita por Bisdom et al. (1982). Ocorre uma descoloração do mineral, abaixamento da birrefingência, abertura das lamelas em leques, segregação do ferro de seu retículo cristalino e alojamento nos espaços interlamelares na forma de óxi-hidróxidos. Os vazios interlamelares criados durante a alteração podem ser ocupados por produtos diversos.

Mineralogicamente, a biotita se altera em assembléias de interestratificados mica-vermiculita e em vermiculita intergrade, que possui uma camada do tipo hidróxi-aluminosa desorganizada entre os folhelhos de vermiculita. A formação deste mineral, também conhecido como Al-vermiculita, é um fenômeno bem conhecido em meios ácidos (Jackson 1963, Tardy \& Gac. 1968, Robert 1975).

Esses filossilicatos secundários contêm cobre e apresentam três tipos diferentes de plasma interlamelar:

- material incolor, constituŕdo de caulinita e haloisita sem cobre;

- material ferruginoso de cor castanha proveniente de exsudação do ferro da antiga biotita, com teores em cobre relativamente baixos (Foto 5 ); $\mathrm{e}$

- material preto com teores em manganês e cobre elevados ( $70 \%$ em $\mathrm{MnO}$ e $23 \%$ em CuO) (Foto 6 ).

Existem, portanto, descontinuidades geoquímicas e morfológicas na alteração das biotitas, indicando acumulações absolutas comparáveis às da alteração das granadas (Tab.3).

O meio fissural $\mathrm{O}$ material de alteração estudado apre- 
Tabela 2 - Análises microgeoquimicas dos produtos de alteração das granadas

\begin{tabular}{|c|c|c|c|c|c|c|c|c|c|c|c|c|}
\hline Material & $\begin{array}{c}\text { Amostra } \\
\text { n. }\end{array}$ & $\mathrm{SiO}_{2}$ & $\mathrm{Al}_{2} \mathrm{O}_{3}$ & $\mathrm{TiO}_{2}$ & $\mathrm{FeO}$ & $\mathrm{MnO}$ & $\mathrm{CaO}$ & $\mathrm{MgO}$ & $\mathrm{CuO}$ & $\mathrm{K}_{2} \mathrm{O}$ & $\mathrm{Cr}_{2} \mathrm{O}_{3}$ & Total \\
\hline Granada sã & & 35,23 & 20,78 & - & 36,30 & 3,84 & 1,43 & 1,87 & - & - & - & 99,45 \\
\hline Plasma 1 & CAC 17 & 26,21 & 12,63 & - & 38,95 & 0,43 & - & 3,42 & 2,65 & 0,29 & 0,25 & 84,83 \\
\hline Plasma 2 & CAC 17 & 33,09 & 3,75 & - & 44,30 & - & - & - & 2,78 & 0,40 & - & 84,32 \\
\hline Plasma 3 & $\begin{array}{l}\text { CAC } 21 \\
\text { CAC } 17 \\
\end{array}$ & $\begin{array}{r}5,32 \\
10,98 \\
\end{array}$ & $\begin{array}{r}13,61 \\
3,68 \\
\end{array}$ & - & $\begin{array}{l}58,35 \\
65,97 \\
\end{array}$ & - & - & - & $\begin{array}{l}3,78 \\
5,70 \\
\end{array}$ & $\begin{array}{c}0,25 \\
- \\
\end{array}$ & - & $\begin{array}{l}81,31 \\
86,33 \\
\end{array}$ \\
\hline Plasma 4 & $\begin{array}{l}\text { CAC } 23 \\
\text { CAC } 7 \\
\text { CAC } 4\end{array}$ & $\begin{array}{l}8,00 \\
4,39 \\
5,19 \\
\end{array}$ & $\begin{array}{l}4,64 \\
8,01 \\
6,29 \\
\end{array}$ & $\begin{array}{c}- \\
- \\
0,34 \\
\end{array}$ & $\begin{array}{l}67,84 \\
60,57 \\
73,07 \\
\end{array}$ & $\begin{array}{c}- \\
- \\
0,24\end{array}$ & $\begin{array}{l}- \\
- \\
- \\
\end{array}$ & $\begin{array}{l}- \\
- \\
- \\
\end{array}$ & $\begin{array}{l}0,54 \\
3,20 \\
4,91 \\
\end{array}$ & $\begin{array}{l}- \\
- \\
- \\
\end{array}$ & $\begin{array}{c}- \\
0,20 \\
- \\
\end{array}$ & $\begin{array}{l}81,02 \\
76,37 \\
90,04 \\
\end{array}$ \\
\hline Plasma 5 & $\mathrm{CAC} 7$ & 5,05 & 7,72 & 0,22 & 62,80 & - & - & - & 3,78 & - & 0,28 & 79,85 \\
\hline Plasma 6 & $\mathrm{CAC} 4$ & 11,17 & 6,98 & - & 64,89 & - & - & - & 1,89 & - & - & 84,93 \\
\hline
\end{tabular}

Amostras e respectivas profundidades: CAC 4, 1,8 m; CAC 7, 3,5 m; CAC 17, 14,0 m; CAC 21, 19,5 m; CAC 23, 23,5 m; e CAC 25 , $28,0 \mathrm{~m}$.

senta um meio fissural importante, em que diversos tipos de fissuras estão presentes, caracterizadas pela natureza dos materiais de preenchimento. De uma maneira geral, podemos dizer que sua natureza varia em função da posição que o meio fissural ocupa dentro do perfil de alteração.

$\mathrm{Na}$ base do perfil encontram-se, principalmente, três tipos de fissuras:

- fissuras com malaquita, que aparecem no contato com a rocha fresca;

- fissuras com materiais verdes, que ocorrem na rocha alterada, apresentando espessuras muito varíaveis. Ao microscópio optico observa-se muitas vezes tratar-se de uma mistura esmectita + malaquita. Essas fissuras são cortadas por outras preenchidas só com malaquita; $\mathrm{e}$

- fissuras com esmectitas castanhas.

Na parte superior do perfil, outros tipos de preenchimen. tos do meio fissural são característicos:

- fissuras com preenchimento de um material incolor desprovido de cobre. A morfologia deste material, observada ao microscópio eletrônico de varredura, é constituída por tubos semelhantes à haloisita;

- fissuras com preenchimento alaranjado, constituído por óxi-hidróxidos de ferro com teores em cobre de menos de $3 \%$ em CuO; $\mathrm{e}$

- fissuras com preenchimento preto muito abundante em certos níveis, constituídos por criptomelana mal-cristalizada; este produto é o mesmo encontrado nas pseudomorfoses das granadas e das biotitas (Foto 6). No topo do perfil, as análises indicam teores maiores que $25 \%$ em CuO neste tipo de material.
Plasmas: 1. de cor heterogênea castanha a preta; 2. Grânulos de cor amarela e laranja; 3. laranja, associados às relíquias de granada; 4 . baranja das pseudomorfoses totais; 5 . castanho; e 6. vermelho.

Em muitas fissuras, os três preenchimentos ocorrem concomitantemente e, nestes casos, estas três fases depositaram-se na seguinte ordem: 1) depósito ferruginoso alaranjaso; 2) depósito manganesífero; e 3) depósito sílico-aluminoso incolor.

A LOCALIZAÇÃO DO COBRE NOS PRODUTOS DE ALTERAÇÃo As observações efetuadas em escala microscópica mostram uma certa diversificação das fases suporte do cobre, segundo a profundidade e o fácies conside* rado.

Nas alterações pseudomórficas das granadas e dos anfibó. lios, o cobre está principalmente ligado aos óxi-hidróxidos de ferro, fato já assinalado por Veiga \& Schorscher 1982. Entretanto, na alteração dos anfibólios, os teores em cobre aumentam regularmente em direção aos níveis mais evoluídos, o que não ocorre com o ferro (Fig. 4). Este fato mostra uma certa independência de comportamento entre cobre e ferro nos primeiros estágios de alteração.

Existe uma correlação marcante entre ferro e cobre nos plasmas formados pela alteração das granadas (Fig. 5). Dois grupos de amostras fogem desta tendência: $a$ ) plasma do tipo alaranjado em amostras profundas e $b$ ) plasma do tipo vermelho, alternado com o alaranjado, no qual o primeiro tem menos cobre e sílica, e parece ser derivado do segundo por uma redistribuição daqueles elementos (Fig. 6).

O material manganesífero das fissuras representa a me. lhor armadilha para o cobre (Fig. 7). Sem dúvida, esta armadilha parece ser muito mais eficiente nos niveis superficiais que nos inferiores, onde os teores em cobre são sempre bem mais baixos.

Tabela 3 - Análises microgeoquímicas dos produtos de transformaçau aas biotitas

\begin{tabular}{|c|c|c|c|c|c|c|c|c|c|c|c|c|c|c|c|c|c|c|c|c|c|c|c|c|c|c|}
\hline & \multicolumn{4}{|c|}{$\mathrm{CAC} 23$} & \multicolumn{3}{|c|}{ CAC 21} & \multicolumn{5}{|c|}{ CAC 17} & \multicolumn{7}{|c|}{ CAC 7} & \multicolumn{7}{|c|}{ CAC 4} \\
\hline & 1 & 2 & 3 & 4 & 5 & 6 & 7 & 8 & 9 & 10 & 11 & 12 & 13 & 14 & 15 & 16 & 17 & 18 & 19 & 20 & 21 & 22 & 23 & 24 & 25 & 26 \\
\hline $\mathrm{SiO}_{2}$ & 33.28 & 34,97 & 36,74 & 40,63 & 28,74 & 34,48 & 27,95 & 29,90 & 28,33 & 30,99 & 31,65 & 32,85 & 29,08 & 28,46 & 32,97 & 31,58 & 28,56 & 30,48 & 27,89 & 29,13 & 30,19 & 30,05 & 29,82 & 38,85 & 31,19 & 38,79 \\
\hline $\mathrm{Al}_{2} \mathrm{O}_{3}$ & 20,14 & 19,55 & $21,2\}$ & 26,14 & 13,24 & 20,75 & 12,59 & 14,02 & 11,97 & 13,65 & 13,78 & 14,14 & 12,43 & 14,37 & 18,81 & 13,36 & 12,39 & 12,91 & 11,49 & 11,10 & 11,79 & 12,06 & 12,52 & 14,38 & 12,49 & 13,35 \\
\hline $\mathrm{TiO}_{2}$ & 0,84 & 1,04 & 1,08 & 0,46 & 2,62 & 1,83 & 2,30 & 2,01 & 1,47 & 1,65 & 1,64 & 1,47 & 1,41 & 3,01 & 1,21 & 1,57 & 1,40 & 1,28 & $\$, 57$ & 0,42 & 0,44 & 1,69 & 1,74 & 1,48 & 1,31 & 1,57 \\
\hline Ino & 13,71 & 15,71 & 12,38 & 14,10 & 26,27 & 19,85 & 26,11 & 24,66 & 30,77 & 27,81 & 23,88 & 26,09 & 23,29 & 18,64 & 16,06 & 22,76 & 18.95 & 23,57 & 19,73 & 28,66 & 26,87 & 22,86 & 24,82 & 24,20 & 24,50 & 25,69 \\
\hline $\mathrm{MnO}$ & 1,30 & 1,31 & 0,93 & 0,17 & - & - & $\ldots$ & - & - & - & - & - & - & 1,19 & 0,42 & 0,39 & - & 0,26 & - & - & - & 0,36 & 1,05 & - & - & - \\
\hline $\mathrm{MgO}$ & 1,41 & 1,85 & 0,77 & 0,50 & 3,25 & 2,09 & 2,80 & 2,91 & 5,50 & 4,53 & 6,01 & 4,05 & 4,13 & 4,13 & 3,04 & 3,93 & 3,83 & 4,04 & 4,02 & 5,05 & 5,69 & 5,85 & 5,83 & 5,55 & 5,90 & 6,41 \\
\hline $\mathrm{CuO}$ & 0,55 & 0,47 & 0,38 & 0,27 & 13,20 & 6,76 & 10,33 & 11,55 & 3,34 & 6,49 & 11,13 & 6,09 & 6,59 & 6,04 & 5,12 & 5,48 & 7,31 & 6,87 & 6,46 & 5,46 & 5,77 & 9,58 & 10,40 & 6,41 & 6,13 & 6,24 \\
\hline $\mathrm{K}_{2} \mathrm{O}$ & 3.72 & 4,57 & 4,12 & 4,44 & 0,88 & 1,68 & 1,15 & 2,47 & 4,10 & 4,16 & 2,18 & 4,83 & 3,96 & 1,84 & 2,32 & 5,44 & 3,33 & 4,52 & 2,72 & 5,21 & 5,32 & 2,15 & 2,57 & 4,99 & 5,20 & 4,95 \\
\hline Total & 74.95 & 79,47 & 77,60 & 86,71 & 88,20 & 87,44 & 83,23 & 87,52 & 85,55 & 89,42 & 90,37 & 89,75 & 80,89 & 77,68 & 79,95 & 84,51 & 75,77 & 83,94 & 74,33 & 85,25 & 86,47 & 84,74 & 88,91 & 90,08 & 87,07 & 91,81 \\
\hline
\end{tabular}




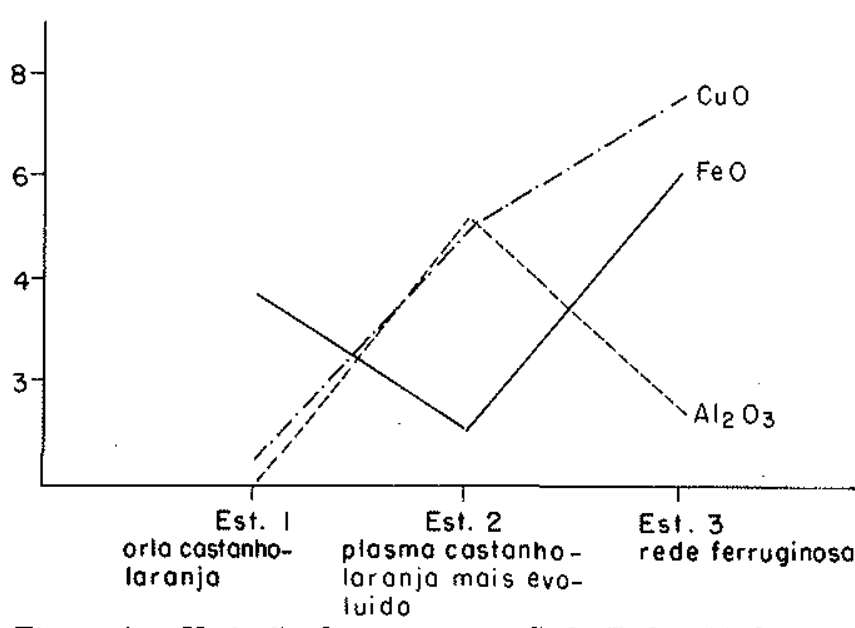

Figura 4 - Variação dos teores em $\mathrm{CuO}, \mathrm{FeO}$ e $\mathrm{Al}_{2} \mathrm{O}_{3}$ nos três diferentes estágios de alteração dos anfibólios

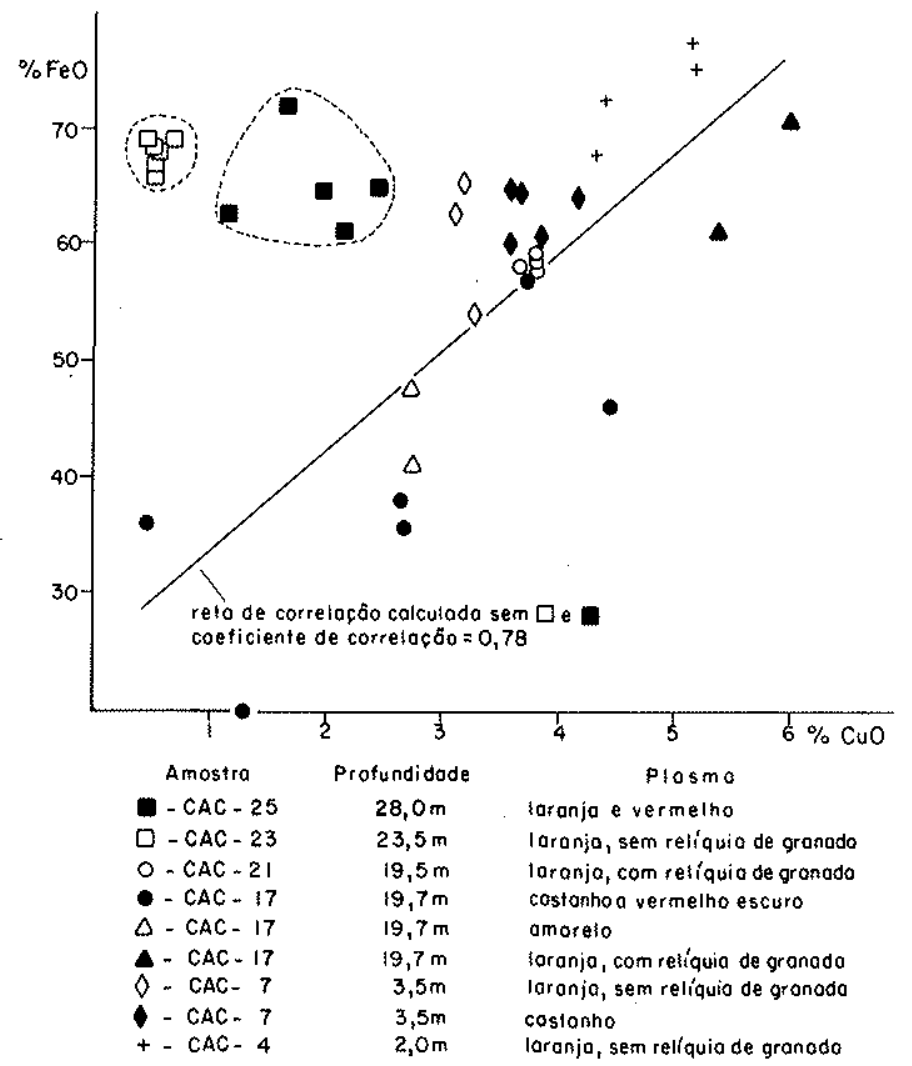

Figura 5 - Correlação entre os teores em $\mathrm{CuO}$ e $\mathrm{FeO}$ nos produtos de alteração das granadas

Nos produtos de alteração da biotita, a correlação entre potássio e cobre é negativa, ou seja, quanto mais alterada a biotita mais cobre ela contém (Fig. 8). Os testes de aquecimento para difração de raios $\mathrm{X}$ indicam um fechamento parcial da estrutura a $10,69 \AA$ e a $4500 \mathrm{C}$ (vermiculita normal fecha a $10 \AA$ e a $4000^{\circ}$ ). As curvas de ATD mostram um pico endotérmico a $490^{\circ} \mathrm{C}$. Esses resultados indicam a presença de uma camada de hidróxidos nos espaços interfoliares destruída a $490^{\circ} \mathrm{C}$; o cobre poderia estar presente nesta camada formando ligações $\mathrm{Cu}-\mathrm{OH}$, mas não em quantidade suficiente para formar estruturas do tipo cloreto (muito estáveis), pois, a $600^{\circ} \mathrm{C}$, o fechamento a $10 \AA$ é completo.

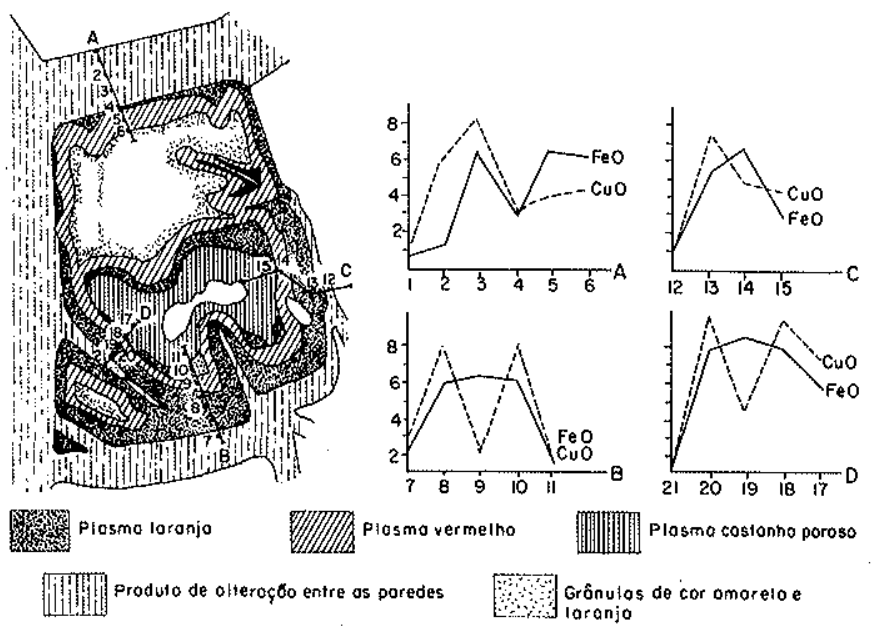

Figura 6 - Variação dos teores em CuO e FeO. Perfil em pseudomorfose de granada (amostra CAC 4)

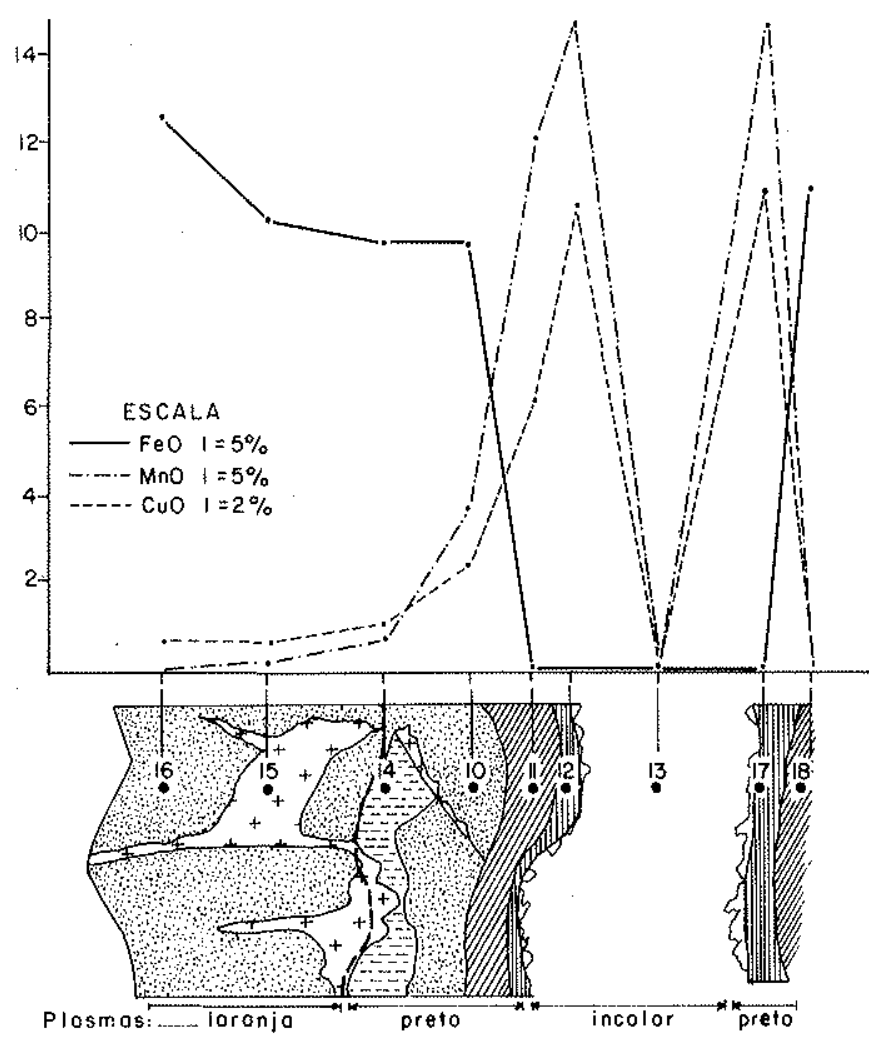

Figura 7 - Variação dos teores em $\mathrm{CuO}, \mathrm{FeO}$ e $\mathrm{MnO}$. Perfil cortando os cutanes de preenchimento de uma fissura (laranja, preto e incolor)

Os testes de troca de cátions revelaram a natureza nãotrocável dos cátions (CTC $=15$ a $25 \mathrm{meq} / 100 \mathrm{~g}$ enquanto em uma vermiculita magnesiana a CTC é de $150 \mathrm{meq} / 100$ g).

Os cálculos da fórmula estrutural dos filossilicatos de alteração, na base de $24(\mathrm{O}, \mathrm{OH})$ (Tab. 4), indicam que uma parte do cobre deve entrar na estrutura para completar a camada octaédrica a seis átomos. Embora teóricas, essas fórmulas indicam que o cobre poderia ocupar posiçōes octaédricas e interfoliares não-trocáveis.

CONCLUSÕES Sintetizando os resultados apresenta- 

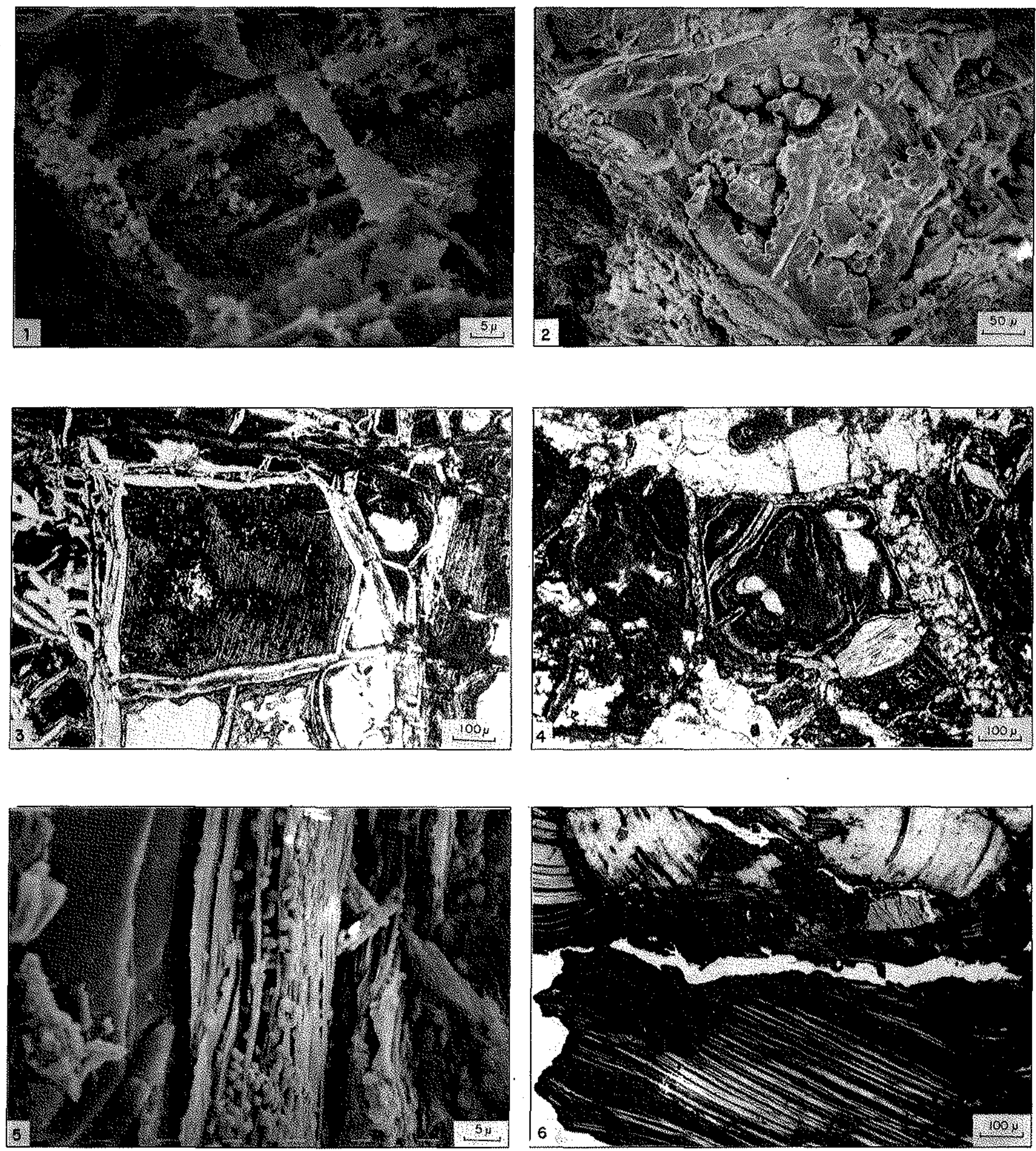

Prancha 1: Foto 1 - Pseudomorfose total de anfibólios por formação de uma rede ferruginosa constituida por goethita em forma de rosetas (estágio 3). Amostra CAC 21. Microscópio eletrônico de varredura; Foto 2 - Pseudomorfose total de granadas por um plasma ferruginoso. Microscópio eletrônico de varredura; Foto 3 - Pseudomorfose total de granadas por plasma laranja, que se transforma no centro em plasma castanho poroso. Micrografia em L.N.; Foto 4 - Alteração de granadas. Associação de um plasma laranja e de um vermelho. Micrografia em L.N.; Foto 5 - Alteraf̧ão de biotitas. Alargamento do conjunto de folhetos. Nos vazios interlamelares $e$ sobre as bordas existe acumulação de ferro sob a forma de grânulos. Microscópio eletrônico de varredura; Foto 6 - Alteração de biotitas. Nota-se a presença de fissuras que recortam as biotitas alteradas paralelamente aos traços da clivagem. Produtos manganesiferos e ricos em cobre invadem os espaços interlamelares. Micrografia L.N (material branco). 


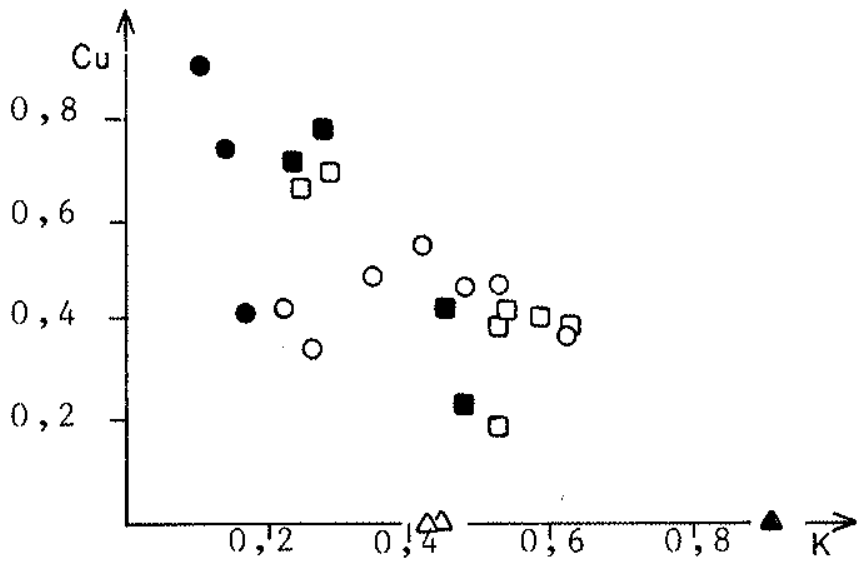

Figura 8 - Correlação entre os teores em Cu e K nas biotitas alteradas nos diferentes niveis do perfil de intemperismo (Cu e K calculados na base de 11 O)

Tabela 4 - Fórmulas estruturais dos produtos de transformação das biotitas da amostra CAC 4 (base 240 )

\begin{tabular}{l|c|c|c|c|c|c|c}
\hline $\mathrm{Si}$ & 5,46 & 5,50 & 5,48 & 5,28 & 5,56 & 5,54 & 5,52 \\
\hline $\mathrm{Al} I \mathrm{~V}$ & 2,44 & 2,50 & 2,52 & 2,52 & 2,44 & 2,46 & 2,48 \\
\hline $\mathrm{Fe} \mathrm{IV}$ & 0,10 & - & - & - & - & - & - \\
\hline $\mathrm{Al}$ & - & 0,04 & 0,06 & 0,10 & 0,42 & 0,16 & 0,16 \\
\hline $\mathrm{Ti}$ & 0,06 & 0,06 & 0,22 & 0,22 & 0,18 & 0,18 & 0,20 \\
\hline $\mathrm{Fe}+$ & 4,38 & 4,10 & 3,48 & 3,68 & 3,42 & 3,64 & 3,62 \\
\hline $\mathrm{Mn}$ & - & - & 0,06 & 0,16 & - & - & - \\
\hline $\mathrm{Mg}$ & 1,40 & 1,54 & 1,58 & 1,54 & 1,40 & 1,56 & 1,62 \\
\hline $\mathrm{Cu}$ & 0,16 & 0,26 & 0,60 & 0,30 & 0,58 & 0,46 & 0,40 \\
\hline $\mathrm{Cu}$ & 0,58 & 0,54 & 0,72 & 1,08 & 0,29 & 0,36 & 0,40 \\
\hline $\mathrm{K}$ & 1,24 & 1,24 & 0,50 & 0,58 & 1,08 & 1,18 & 1,06 \\
\hline
\end{tabular}

dos, pode-se dizer que nas transformaçð̄es pseudomórficas das granadas e dos anfibólios, ocorre a eliminação de todos os elementos, a exceção do Fe. No caso das transformações das biotitas em interestratificados mica-vermiculita e em vermiculita intergrade, que são preservadas até níveis mais superiores, a eliminação dos elementos é menos marcante, a menos do $\mathrm{K}$ e $\mathrm{Mg}$, que são mais eficientemente lixiviados.

A conclusão mais significativa é a respeito da fixação do cobre nos produtos de alteração; este elemento, ausente nas estruturas dos minerais primários, é fixado pelos produtos secundários. Isto mostra que os altos teores em cobre no manto de imtemperismo estão diretamente relacionados ao processo da alteração supérgena, contrariamente ao que acontece em outras jazidas sulfetadas com recobrimento ferralítico, em que a maior parte do cobre é lixiviado ( $\mathrm{Pa}$. risot \& Melfi 1983).

No manto de alteração da jazida do Salobo $3 \mathrm{~A}$, o cobre encontra-se retido em, principalmente, três fases:

- nos óxi-hidróxidos de Fe das pseudomorfoses de anfibólio e granada;

- nos filossilicatos de transformação das biotitas;

- nos produtos manganesíferos de preenchimento de fissuras nas partes mais altas dos perfis.

Dessas três fases, a mais significativa é certamente a dos óxi-hidróxidos de ferro, que, embora com teores em cobre menores que os apresentados pelos filossilicatos e produtos manganesíferos, é muito mais abundante e, portanto, representa um peso maior nos teores médios.

Agradecimentos Os autores desejam expressar seus agradecimentos à Rio Doce Geologia e Mineração (Docegeo), pelas facilidades oferecidas durante o desenvolvimento da pesquisa, à Fundação de Amparo à Pesquisa do Estado de São Paulo (FAPESP) e à Financiadora de Estudos e Projetos (Finep), pelo apoio financeiro, sem o qual seria impossível a realização deste trabalho.

\section{REFERENCIAS BIBLIOGRÁFICAS}

BASSET, W.A. - 1958 - Copper vermiculites from northern Rhodesia. The Am. Min., 48:1112-1133.

BISDOM, E.B.A.; STOOPS, G.; DELVIGNE, J.; CURMI, P.; ALTEMULLER, H.J. - 1982 - Micromorphology of weathering biotite and its secondary products. Pedologie, XXXII (2):225-252.

BORGES MARTINS, L.P.; SAUERESSIG, R.; MELO VIEIRA, M.A. - 1982 - Aspectos petrográficos das principais litologias da sequêencia Salobo. In: SIMPOSIO DE GEOLOGIA DA AMAZÔNIA, 1, Belém, 1982, Atas... p. 253-262.

DEER, W.A.; HOWIE, R.A.; ZUSSMANN, J. - 1962 - Rock forming minerals. London. Longmans, 12 ed., $528 \mathrm{p}$.

EMBRECHTS, J. \& STOOPS, G. - 1982 - Microscopical aspects of garnet weathering in umid tropical environment. J. Soil Sci. 33:535-545.

JACKSON, M.L. - 1963 - Interlayering of expansible layer silicates in soils by chemical weathering. Clays and Clay Minerals, 11th Nat. Conf.: 29-46.

PARISOT, J.C. \& MELFI, A.J. - 1983 - Lateritic alteration of metasedimentary rocks with copper sulphide mineralization in Central-Brazil. In: INTERN. SEM. LAT. PROCESSES, 2, São Paulo, 1982, Proceedings..., São Paulo, p. 185-196.

PARISOT, J.C.; DELVIGNE, J.; GROKE, M.C.T. - 1983 Petrographical aspects of the supergene weathering of garnet in the "Serra dos Carajás" (Pará-Brazil). Sciences Géologiques, Mémoires 73(2): 141-148.

ROBERT, M. - 1975 - Principes de détermination qualitative des minéraux argileux à l'aide des rayons-X. Ann. Agron, 26(4):363-399.

SARAZIN, G.; ILDEFONSE, Ph.; MULLER, J.P. - 1982 - Contrô* le de la solubilité du fer et de l'aluminium en milieu ferrallitique. Geoch. Cosmoch. Acta, 46:1267-1279.

TARDY, Y. \& GAC, J.Y. - 1968 - Minéraux argileux et vermiculite-A1 dnas quelques sols et arènes des Vosges. Hypothèse sur la neoformation des minéraux à $14 \AA$ A Bull. Serv. Carte Geol. Als. Lorr, 2(1-4):285-304.

VEIGA, M.M. \& SCHORSCHER, H.D. - 1982 - Caracterização tecnológica da relação cobre-óxidos hidratados de ferro no minério "oxidado" de cobre de Carajás, Marabá, PA, Brasil. In: 1.0 ENCONTRO DO HEMISFERIO SUL SOBRE TECNOLOGIA MINERAL e 9. ENCONTRO NACIONAL DE TRATAMENTO DE MINERRIO E HIDROMETALOGIA, 1982, p. 606-613.

MANUSCRITO

Recebido em 23 de maio de 1985 Revisão aceita em 18 de abril de 1986 